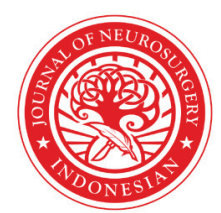

\title{
Improvement of motoric and sensory functional after surgical resection craniovertebral junction meningioma: a case report
}

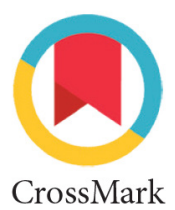

\author{
Novan Krisno Adji ${ }^{*}$, Rudy Gunawan ${ }^{1}$, Achmad Ma'ruf Fauzi ${ }^{1}$
}

\section{ABSTRACT}

Background: Meningioma of the craniovertebral junction is a unique and rare case. The sensitivity of the region to surgical still debateable. Complete resection is the primary goal of surgery. Aim: We report a unique and rare case of improvement motoric and sensory after surgical resection intramedullary craniovertebral junction meningioma.

Case report: 37 years old woman presented tetraplegia (0/0/0/0) and heavy breathing since six month. MRI showed mass on craniovertebral junction. Laminectomy (1, tumor excision, and suboccipital decompression should be done. One week post operation the patient showed an improvement in functional motoric $(3 / 3 / 2 / 2)$ and sensory and improvement in clinical symptoms.

Conclusion: Complete resection is the primary goal to prevent sequel and recurrent craniovertebral junction meningioma.

Keywords: Craniovertebral junction meningioma, Laminectomy, Complete resection, Suboccipital decompression

Cite This Article: Gunawan, R., Adji, N.K., Fauzi, A.M. 2020. Improvement of motoric and sensory functional after surgical resection intramedularry craniovertebral junction meningioma: A case report. Indonesian Journal of Neurosurgery 3(3): 71-73. D0I: 10.15562/ijn. v3i3.74

'Department of Neurosurgery, Soebandi General Hospital Jember University, Jember, Indonesia
*Corresponding to: Novan Krisno Adji; Department of Neurosurgery, Soebandi General Hospital Jember University, Jember, Indonesia; novanns21@gmail.com
Received: 2019-07-19

Accepted: 2020-05-09 Published: 2020-11-19

\section{INTRODUCTION}

Meningioma of the craniocervical junction present a unique and rare diagnosis among meningioma. They originate from the meninges of the lower part of the clivus and the upper edge of the axis, laterally from the jugular tubercle to the upper aspect of the C-2 lamina. ${ }^{1}$ This accident is account for $1.8 \%$ to $3.2 \%$ of central nervous system (CNS) meningiomas. ${ }^{2,3}$ Their indolent development and the wide subarachnoid space at this level at the craniovertebral junction makes clinical diagnosis difficult, complex, and often lead to a long interval between onset of symptoms and diagnosis.,4 The sensitivity of this region to surgical manipulation has sparked recent debate as to the most advantageous surgical approach. ${ }^{2}$ Surgical management of these lesions is complex and complete resection should be the primary goal of surgery but it is often difficult to do because their tendency to encase/ dislocate vital structures such as the vertebrobasilar complex, brain stem, and the lower cranial nerves (LCNs). ${ }^{1,3,5}$

\section{CASE REPORT}

37 years old woman comes with tetraplegi 0/0/0/0 and heavy breathing since six months ago. The patient also complained motoric and sensory deficit, occipital headache, neck pain, otalgia, and urinary incontinence. Neurosurgeon decided cervical MRI to figure out abnormality of the cervical spine. MRI showed mass on craniovertebral junction sagittal (Figure 1) and axial (Figure 2). Neurosurgeon planned to do laminectomy $\mathrm{C} 1$, tumor excision, and suboccipital decompression.

One week post operation, the patient showed an improvement in motoric 3/3/2/2 and sensory functional, decrease heavy breathing, occipital headache, neck pain, otalgia, and urinary incontinence.

\section{DISCUSSION}

Their indolent development and the wide subarachnoid space at this level at the craniovertebral junction makes clinical diagnosis difficult, complex, and often lead to a long interval between onset of symptoms and diagnosis., ${ }^{2,4}$ the common clinical manifestations of cervical meningioma are suboccipital headache, neck pain, radicular pain, motoric and sensory deficit, tetraparesis until tetraplegia, hand atrophy and spasticity, pathology reflex, urinary incontinence. ${ }^{6}$ Besides the symptoms describe above, in this case the patient also feel heavy breathing because cervical 3 innervate diapraghm. ${ }^{7}$

The gold standard for diagnosis craniovertebral junction meningioma is MRI. Magnetic resonance imaging (MRI) provides high-resolution pictures of the tumor and gives important information for surgical planning, such as its relationship to the brainstem and surrounding structures including 


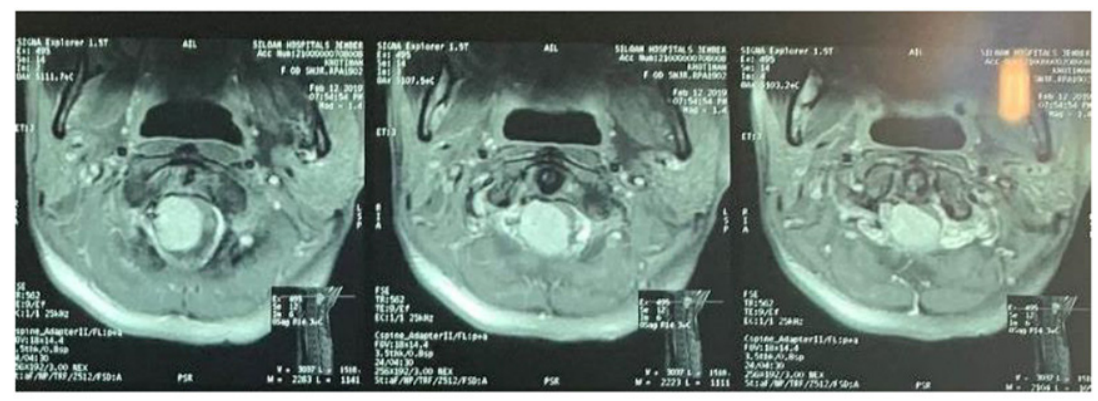

Figure 1. T1 sagittal cervical MRI showed mass on craniovertebral junction

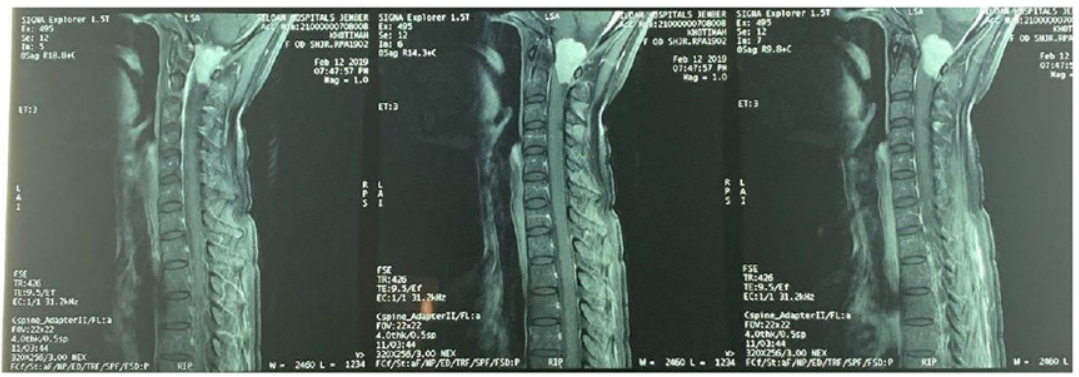

Figure 2. T1 axial cervical MRI showed mass on craniovertebral junction

\section{Table 1. WHO Meningioma Grading}

\section{WHO Grade I}

Benign meningioma
Histologic variant other than clear cell, chordoid, papillary,
and rhabdoid
Lacks criteria of grades II and III meningiomas

WHO Grade II

Atypical meningioma
Mitotic index $\geq 4$ per 10 high-power fields
or
At least 3 of 5 parameters:
Sheeting architecture (loss of whorling and/or fascicles)
Small cell formation (high $\mathrm{N} / \mathrm{C}$ ratio)
Macronucleoli
Hypercellularity
Spontaneous necrosis (i.e., not induced by embolization or
radiation)
or
Brain invasion
or
Clear cell meningioma
or
Chordoid meningioma

\section{WHO Grade III}

Anaplastic (malignant) meningioma

Mitotic index $\geq 20$ per 10 high-power fields or

Frank anaplasia (sarcoma, carcinoma, or melanoma-like histology)

or

Papillary meningioma

or

Rhabdoid meningioma

* N/C indicates nuclear/cytoplasmic. vital vasculature. Typically, meningiomas are isointense on T1-weighted imaging and isointense to hypointense on T2-weighted imaging. With gadolinium administration, they avidly enhance. Magnetic resonance angiography (MRA) may be used pre-operatively for surgical planning as an alternative to standard angiography. MRA can allow clinicians to assess the patency of the vertebral artery. MRV (magnetic resonance venogram) may also be used to evaluate vital dural venous sinuses that may be in the proposed operative trajectory. Plain $\mathrm{x}$-rays of the craniocervical junction may reveal subtle change such as calcification or erosion around the foramen magnum. They may also show widening of the interpedicular spaces of upper cervical vertebrae. ${ }^{8}$

The sensitivity of this region to surgical manipulation has sparked recent debate as the most advantageous surgical approach. ${ }^{2}$ Surgical management of these lesions is complex because of their tendency to encase/ dislocate vital structures such as the vertebrobasilar complex and the lower cranial nerves (LCNs). ${ }^{3}$ Complete resection should be the primary goal of surgery. ${ }^{1}$ In this case we do tumor excision, laminectomy C1, and suboccipital decompression. World Health Organization classified into 3 subdivisions based on histopathology (Table 1) and Simpson grading system classified into 5 subdivisions (Table 2) for assessing the recurrent of meningioma., ${ }^{910}$ The lack of this case we didn't do histopathology of the meningioma so we couldn't classified based on histopathology. But we do macroscopically complete with removal of affected dura and underlying bone based on Simpson grade I.

The extreme lateral transcondylar approach entails removing the condyle either partially or completely. This technique may lead to postoperative instability. One of the factors leading to this instability includes loss of the insertion of the transverse ligament over the lateral mass of C1. Loss of the insertion of the alar ligament over the occipital condyle also contributes, as does loss of part, or the entire cup-shaped articular surface of the occipital condyle. Lastly, destruction of the fibrous capsule around the occipito-atlantal articulation may also contribute, especially if it is violated posteriorly and laterally, where it is the thickest, and provides the most reinforcement. Stabilization procedures of the occipital-cervical region typically involve a plate/ rod system for the occipital bone, with occipital bone screws in the midline keel, $\mathrm{C} 2$ pedicle screws, and lateral mass screw fixation of the sub-axial spine. $^{5}$

Hypoesthesias, paresthesias, pain and sphincter disturbance generally improved steadily after 
Table 2. Simpson Meningioma Grading

\begin{tabular}{ll} 
Simpson grade & Definition \\
\hline I & $\begin{array}{l}\text { Macroscopically complete tumor resection with } \\
\text { removal of affected dura and underlying bone }\end{array}$
\end{tabular}

II

Macroscopically complete tumor resection with coagulation of affected dura only

III

Macroscopically complete tumor resection without removal of affected dura or underlying bone

IV

Subtotal tumor resection

Decompression with or without biopsy

Simpson D. The recurrence of intracranial meningiomas after surgical treatment. J Neurol Neurosurg Psychiatry 1957;20:22-39

surgery. However, although weakness and gait ataxia generally improved at the last follow-up compared to pre-op. ${ }^{11}$ In this case motoric and sensory functional post-surgical resection improved steadily. Pre-operation motoric 0/0/0/0 and hypoesthesia then post-operation motoric $3 / 3 / 2 / 2$ and hypoesthesia (-). Generally other symptom like suboccipital headache, neck pain, radicular pain, and urinary incontinence slowly decrease.

\section{CONFLICT OF INTEREST}

There is no conflict of interest related to the materials or methods used in this study.

\section{FUNDING}

This article received no specific funding from any funding agency in the public, commercial, or notfor-profit sectors.

\section{AUTHORS' CONTRIBUTIONS}

Authors took part in design of the study, contributed to data collection, participated in writing the manuscript and all agree to accept equal responsibility for accuracy of the contents of this article.

\section{REFERENCES}

1. Lasse D, Pedram E, Jakob M, Tammam A, Manfred W, Jan R. Meningiomas of the Craniocervical Junction- A Distinctive Subgroup of Meningioma. PLOS ONE. 2016: 11(4);e0153405.

2. Melfort RB, Michael DC. Foramen Magnum Meningiomas: Concepts, Classifications, and Nuances. Neurosurg Focus. 2003: 14(6); Article 10.

3. Antonino R, Alessandro P, Giada T, Alessandro F, Demo ED, Roberto D. Quality of Life After Craniovertebral Junction Meningioma Resection: Shaping the Real Neurologic and Functional Expectancies about these Surgeries in a Contemporary Large Multicenter Experience. World Neurosurgery. 2018: 110; 583-591.

4. Bruneau M, George B. Classification System of Foramen Magnum Meningiomas. Journal of Craniovertebral Junction and Spine. 2010: 1:3.

5. Michael AG, Timothy B, Aaron B, Eric MD. Meningiomas of the Craniovertebral Junction: a Review. Journal of Spine. 2013: 3(1); 150.

6. Pant, Ishita. Vinod Kumar Singh Gautam. Rima Kumari. Sujanta Chaturvedi. 2012. Spinal Tumor: Primary cervical extradural meningioma unsual location. Departement Neurosurgery: New Delhi India

7. Netter FH. Atlas of Human Anatomy. $7^{\text {th }}$ Edition. Elsevier.

8. Winn HR (2011) Youmans Neurological Surgery. Elsevier Health Sciences.

9. Daniel JB, Joseph EP, Bette KKdM, Anthomy TY, Thomas JM, Philip JB, Suzanne ZP, Richard AP, Roge EM. WHO CNS Tumor Classification. Surgical Neuropathology Update: A Review of Changes Introduced by the WHO Classification Tumours of the Central Nervous System. $4^{\text {th }}$ Edition. Arch Pathol Lab Med. 2008: 132; 993-1007.

10. Donald S. The Recuurence of Intracranial Meningiomas after Surgical Treatment. J. Nurol. Neurosurg. Psychiat. 1957: 20;22-39.

11. Mohamad B, Ting M, Risheng X, Jon W, Alessandro O, Ziya LG, Rafael JT, Henry B, Ali B. Surgical Outcomes of Craniovertebral Junction Meningioma: A Series of 22 Consecutive Patients. Clin Neurol Neurosurg. 2014: 117; 7179.

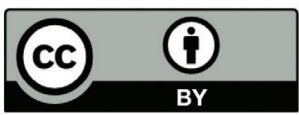

This work is licensed under a Creative Commons Attribution 